\title{
Health technology assessment in Catalonia: An overview of past and future perspectives
}

\author{
Oriol de Solà-Morales \\ Catalan Agency for HTA and Research \\ Alicia Granados \\ Catalan Agency for HTA and Research and MSD España
}

\begin{abstract}
Objectives: The current and past situation of health technology assessment $(\mathrm{HTA})$ in Catalonia is presented in this study.

Methods: The approach used here is a historical review of facts and landmarks.

Results: Spain has undergone radical change in many aspects, but the changes in healthcare provision have been major indeed. Catalonia has had the ability to benefit from these changes and has been able to build upon professionals' experience and expertise to development a consistent HTA network and continuous evaluation paradigm. The early involvement of the Catalan Agency for Health Technology Assessment (CAHTA) in several relevant HTA international initiatives and the relationship of CAHTA and Research with other HTA agencies in Spain is also stressed.

Conclusions: HTA is currently of common use in Catalonia for decision making at different levels. Now emphasis has to be put on the coming challenges that the HTA community will have to face in the coming years: uncontrolled demand, capacity scarcity, a rapidly evolving knowledge frontier, and insufficient input from the economic sphere into evaluations.
\end{abstract}

Keywords: Catalonia, Evaluation, Research, Devolution

\footnotetext{
"A mi me funciona" (it works-out for me). This was a rather common answer when Catalan physicians were challenged about the effectiveness of interventions. Experience was somehow limited to their experience or their colleagues experience (8).

Why and how every health system has taken up policies such as the introduction of health technology assessment (HTA) into decision making-processes is unique and linked to local context. In high-income countries, there has been a need to show that money was spent appropriately, that public efforts persuaded the best possible returns of investments, and that health services were value for money. Within constrained budgets, output improvement became the only way to gain efficiency (4). The appearance of HTA in Catalonia does not differ broadly from other countries (5). There are however, some, particularities that have to be borne in mind and that are worth remembering.
}

\section{THE POLITICAL CONTEXT}

Spain has undergone two major reforms concerning health and health care: the General health Act (1986) and the complete devolution of health and health care to regional authorities (2002), as described in another study (Sampietro et al.) The devolution of health care was far more complex, as it took 20 years to be completed. Catalonia began to manage its own budget and system in 1981, and integrated all the available providers, merging them in broadly three separate subsets: primary health care (publicly funded and provided), public hospital care, and private hospital care (both publicly funded but management and provision remain private). The creation of this network of private providers goes along a long tradition of private healthcare provision in Catalonia, beginning in the nineteenth century and organized around guilds, which had build hospitals and facilities all around 


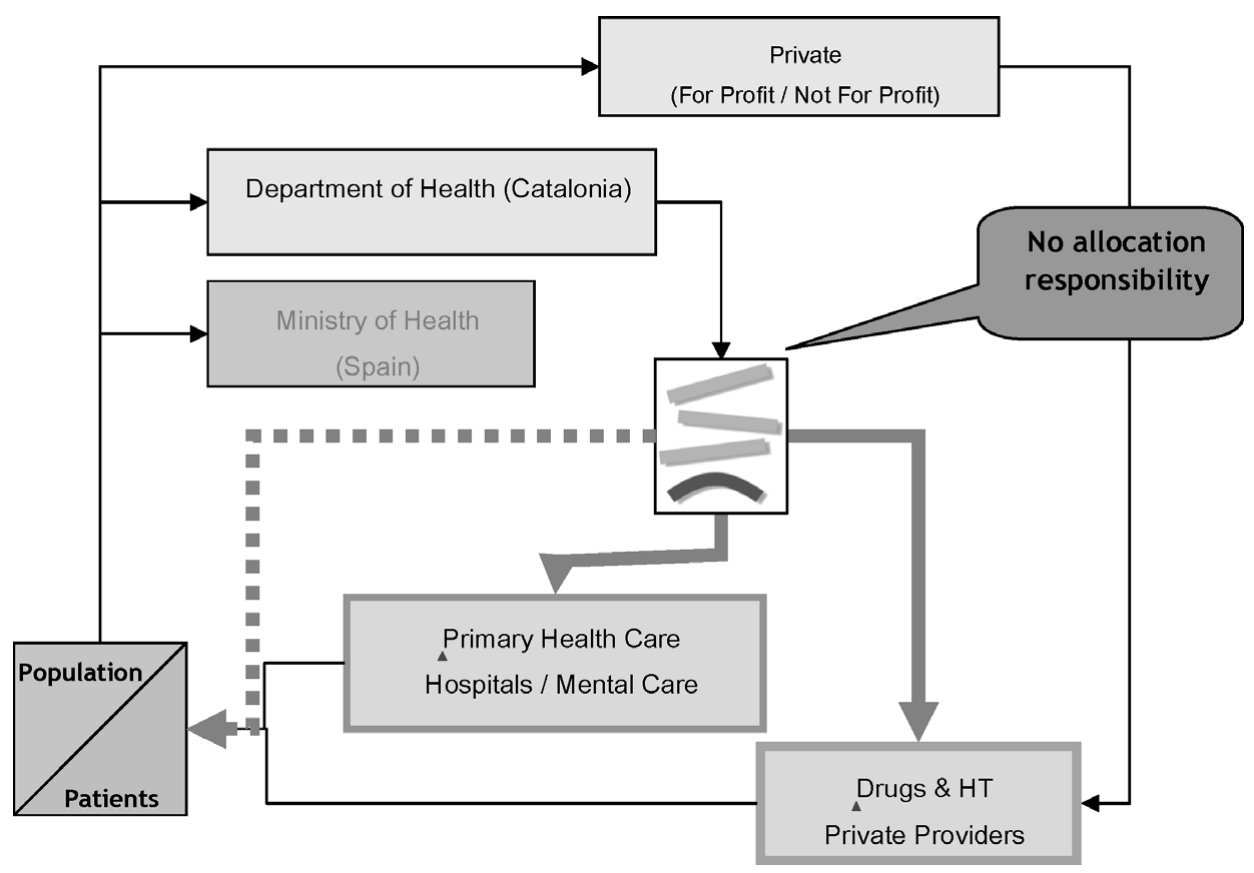

Figure 1. The Catalan healthcare system.

the country, had established social networks to sustain them, and more importantly had entrenched habits or pathways that were deemed as valuable for the newly build health system.

Ten years later, in 1991, the payer and the public providers were separated. More recently, there has been a move toward a further decentralization to smaller newly created local entities, which will be entitled to a certain budget to get the most from their resources by creating synergies within the providers.

This eclectic panorama (Figure 1) of public and private provision has a spill-over effect. Physicians are enabled to pursue and maintain a private practice in addition to their public practice. However, this may create in some cases strange incentives. It is accepted that most physicians and other healthcare professionals have two jobs: in the publicly financed, they are paid a salary (with few incentives) and they receive a fee-for-service income from their private practice. It is notable that approximately 25 percent of the population has complimentary health insurance, which enables it to gain quicker access to some diagnostic and treatment procedures.

\section{HTA IN CATALONIA}

Institutionalized HTA began in Catalonia in 1984, shortly after the devolution of health care, as a response of increasing investment costs in a "young" healthcare system. It first began as an advisory Commission on High Technology, informing decisions about which and where investments in technology should be made. Because this was a rather successful initiative it became, only 4 years after, a Program for HTA and afterward, in 1991, an Office for HTA. After 10 successful years, the Catalan Agency for Health Technology Assessment (CAHTA) was born with enthusiastic physicians with diverse backgrounds, spinning-off a system that was burgeoning in reforms and was at that time built almost from "scratch."

It is important to understand the administrative nature of CAHTA. First of all, it was enacted as a public company. The Department of Health appoints the board of the company, and the board elects a Director, who is accountable for the scientific and administrative fate of the Agency. This gives the company its needed independence but at the same time binds it to policy making. It is also noteworthy that, as a company, it had the ability to sell its services to tenders other than the public healthcare administrators, including Industry. This relationship has been possible and accepted thanks to the strict application of independence, transparency, and ethical principles. The unique administrative nature of the CAHTA has also allowed it to hire the best available professionals.

According to the political tradition in Catalonia, CAHTA was given a consultancy mandate instead of an allocation responsibility. The mission was (is) to inform decisions but not to take them. Although this has its problems, it has been this way since and there have been no formal attempts to change it.

Finally, in 1997 CAHTA changed again to the Catalan Agency for Health Technology Assessment and Research (CAHTAR) due to internal pressures rather than a politically led process (6). After almost 15 years of assessing 


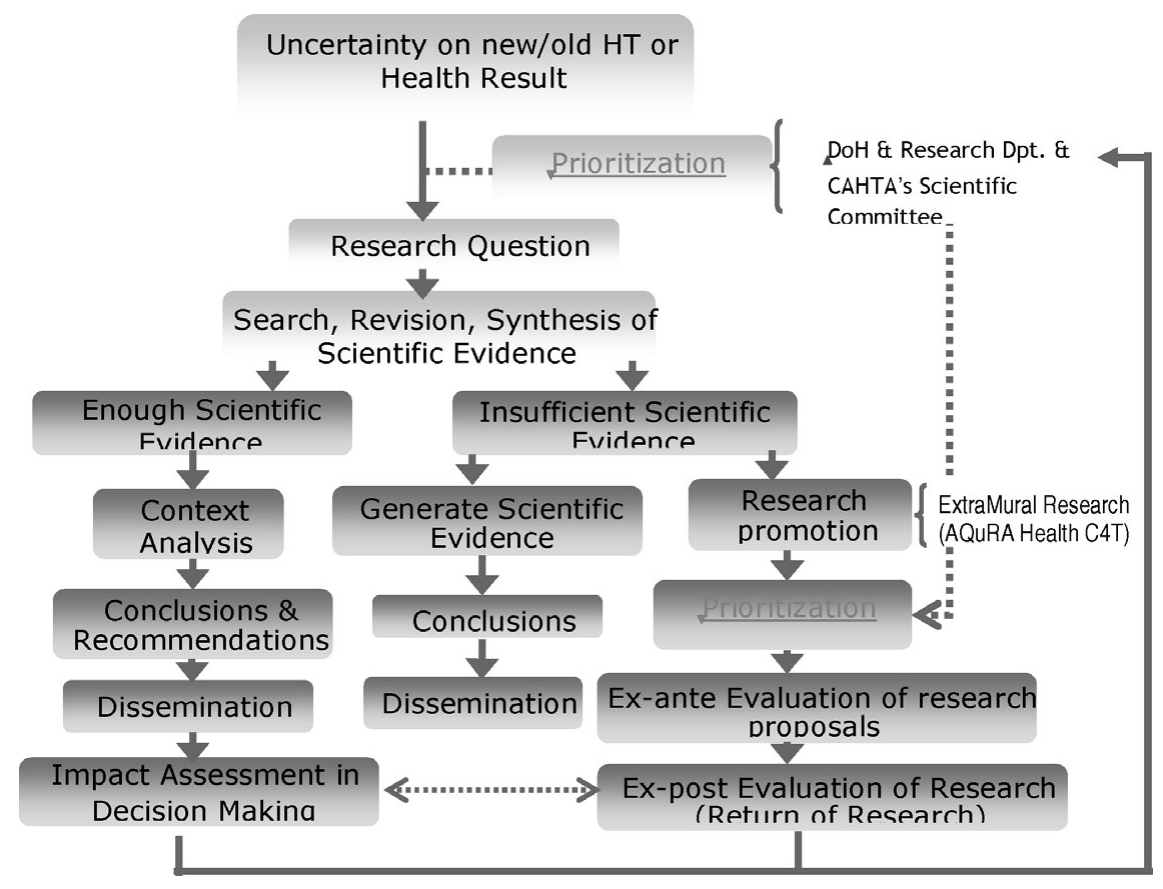

Figure 2. The research priority setting process. DoH, Department of Health; CAHTA, Catalan Agency for Health Technology Assessment.

technologies it was clear that the knowledge and strength of the agency was not only assessing technology, but being able to put together evidence and evaluate it. As the research capacity of the country was increasing, it was also clear that it had to be evaluated and the methodology to do that was already available in the system. Again, it was not an attempt to manage research but to evaluate the research that was financed by the system, and to point out the gaps in knowledge that were found while doing HTA.

Hence, the natural process (Figure 2) would be as it follows: a health technology question would be raised from the system to the Department of Health or directly to CAHTAR, which would evaluate the (best) existing evidence, that is, by reviewing evidence and producing secondary evidence. Should there not be enough conclusive evidence, these should be sought either by doing basic research, that is, generating primary data, or by promoting and financing research elsewhere. The outcomes of either the primary or secondary evidence should fill the knowledge gaps and probably trigger new research questions, which would follow the same process (6).

Healthcare research evaluation is framed within the research programs of the Department of Health, but also of the other Departments of the Government. The goal is not to judge the quality of others' work. The goal is to ensure that the relevant research goals are met, and that the money invested in healthcare research does effectively provide some results. Following from both goals is the idea that the fundamental basis of HTA is the method, establishing the notion that the evaluation method is applicable to any evidence.

In past years, CAHTAR has attempted to gain capacity in quality evaluation. Because quality is an elusive concept, the efforts have been poured in the evaluation of outcome variability in healthcare procedures as a way of diminishing variation itself by making it (publicly) available $(5 ; 10)$. Because some outcomes are rather complex, it raised the need to design outcome evaluation tools, and when tools and practice results were put together, the link between this and Clinical Practice Guidelines was straightforward.

Concerning drug evaluation, CAHTAR participated in the creation of the New Drug Evaluation Commission (Comissió d'Avaluació de Nous Medicaments, CANM) (3) whose objective is to recommend the use (or discontinuation of use) of newly approved for commercialization drugs to general practitioners by grading the comparative therapeutic value of the drug in relation to current standard of care, Although the information is not fully comprehensive, it does indeed guide practitioners in certain circumstances and is clearly an effective tool to exclude noneffective drugs from mainstream consumption.

During these years, CAHTAR has been able to participate in several projects in Europe and elsewhere $(2 ; 7)$, being in 1993 one of the six INAHTA founders and collaborating with Latin-American countries to gain capacity or helping them sort out the model of HTA that should be implemented in their countries. Training has also been an important CAHTA contribution for these countries, and for 
Table 1. HTA Agencies or Units in Spain

\begin{tabular}{ll}
\hline Title & Created in \\
\hline CAHTA(R) & $1984(1994)$ \\
OSTEBA & 1992 \\
Agencia Evaluación Tecnología Sanitaria & 1994 \\
Servicio Canario de Salud & 1995 \\
Agencia Evaluación Tecnología Sanitaria da & 1996 \\
$\quad$ Andalucía & 1999 \\
Avalia T & 2003 \\
IACS & 2003 \\
Agencia laín Entralgo & \\
\hline
\end{tabular}

many others, they have leaned on CAHTA for such programs, especially the international masters program on HTA called Ulysses $(1 ; 9)$.

\section{HTA IN SPAIN}

During these years, other HTA units and agencies were created in Spain, and the awareness toward HTA increased (Table 1). The Ministry of Health is a coordinating body, with international responsibilities but very limited implementation capacity. Civil servants formerly working at the Ministry of Health have been transferred to autonomous communities, and much of the regulation and introduction of new technologies is done at the autonomous/regional level. However, drug registry and regulation is still done at a central level, which ensures equitable access to drugs from a Spanish perspective but does not resolve the capacity of local governments to decide on the basket of goods they want (and are legally enabled to) offer at the regional level.

Unfortunately, the coordination of health and health care is limited: no common policies on contracting, no common policies on prices or reimbursement, ... and no doubt that HTA is not explicitly at the forefront of the political arena. Having said this, we have to acknowledge that recently there have been some successful attempts to establish coordination, by steering the research priorities and giving strong economical support to HTA units and agencies.

\section{CURRENT SITUATION AND FUTURE PERSPECTIVES}

CAHTAR is currently where most European HTA agencies or units are: at a crossroad. CAHTAR is confident from having led the HTA agenda in Catalonia for the past 20 years, and of having introduced evidence analysis on most of the policies that are currently in place. Moreover, we feel especially proud to see that most of the healthcare professionals in Catalonia do not dare to talk about their experience without comparing it with others, without evaluating it, or without showing a Clinical Practice Guideline that backs their decision.

Some of the work done by CAHTAR has been used in important planning policies, and in taking difficult decisions on whether to reimburse or not a proceeding or on how to do priority setting on several issues. Some of our former staff are currently working elsewhere and have been magnificent ambassadors for the evaluative paradigm and have put some rationale in some strategic decisions. Furthermore, CAHTAR has had the ability to broaden its scope of action to a broad range of activities, including basic (health services) research, means by which we have been able to participate in several European and Spanish research networks and programs.

We believe there is no doubt of the work done by CAHTAR in the past years, and yet realize that there is still much more to be done. Like any other unit or agency doing HTA, we face several problems that need to be addressed, the sooner the better.

\section{Demand}

We have been successful in making people understand the need to compare oneself with others, to evaluate the evidence, and to make more informed decisions. However, as new technologies appear, as healthcare provision and arrangements evolve, we face an increasing demand of increasingly difficult tasks.

We are not able to respond to the need of locally adapted Clinical Practice Guidelines. Moreover, because we have not been able to find a faster and more robust method to evaluate technologies within a reasonable time frame, there may be the impression that we do not deliver useful responses, as these come "too late" or when decisions have already been taken. We have been working lately on mini-HTAs, commonly very well accepted by decision makers, but deemed as superficial by the research community.

Again, this poses the question of who do we have to serve best: the research community or decision makers? Should it be methodologically more robust or should we accept that a better informed decision is worth a relative loss of information? From our point of view the answer is simple.

Nevertheless, it is not enough to work on the supply side of the equation. We have to keep on working with managers, healthcare professionals, and macro-level administrators to convince them that evidence gathering and evaluation is something anyone can do at different levels with different efforts and that it may be the case that not all decisions need a full report before a decision can be taken. We also need to make professionals understand that not every region needs its own guideline or recommendation and that it is worthy to adapt or adopt other's work.

In line with this, we should give a clear message to the healthcare community about evidence. After 20 years saying evidence is "the only" robust information we have, we cannot change discourse and now say that evidence is intimately linked to the local setting. We must not get confused about the difference between evidence gathering and evaluation and decision making, which follows a completely different pathway in which, at best, evidence and HTA is only one 
piece of information among others that may be far more relevant to policy and decision makers. Should evidence be the way forward, all health systems would be the same, and an efficient setting/arrangement of providers would have been put in place everywhere. As this is far from being the case, we shall insist on not confusing recommendations with decisions.

\section{Knowledge}

In this rapidly evolving world, the knowledge frontier moves very fast. HTA producers have traditionally done all the jobs: gathering evidence, grading it, and producing recommendations. However, the more the body of knowledge increases, the more difficult it is to keep it on track, especially if one is working in dispersed areas of knowledge. The traditional model of doing is pushed to its end, and HTA agencies and units will have to evolve to new and more dynamic institutions with a "magnet capacity," capable of attracting the best available professionals for a short while and then "using them" to disseminate the newly created knowledge.

There are two opposite strategies: in-house work or outsourcing. One may be more attractive from an agency point of view, but it is much more inefficient; the other is not so gloomy, but is more aligned to professional's need of timely response.

\section{Coordination}

There have been in Europe and around the world several attempts to coordinate the production and adoption of new technologies, but strangely, none have been as successful as they perhaps could have been. It seems that the industry, with diverging and competitive interests, is probably more successful than governments in coordination through their HTA agencies and units, although most of them share a common interest, equivalent missions, and are aligned in their objectives. The incentive is there, but it may not be strong enough.

In Europe, HTA is not a priority, let alone health and public health policies. Most governments are reluctant to incorporate HTA into EU policy, as this may be the back door to a common regulation of healthcare provision. Would governments be willing to pay for reports done elsewhere? Or do they need their "own" report. The EuNetHTA collaboration - financed by EU DG SANCO — has attempted to respond to this (and other) question by building up on a core model of standards, but it is still in its infancy and far from being a ready-made tool. Until it is, we will probably have to fulfill local demands by adapting existing reviews, or by redoing what others have done.

Without a clear and powerful (economic?) incentive, we will probably have to wait to see the coordination. We envisage that a for-profit company will discover this niche and will, soon, be selling their reports, and that will be much more expensive than the money we should have spent for coordination.

\section{Costing and Impact Evaluation}

To our knowledge, no formal attempt has been made to try to establish a cross-over methodology that enables price comparison. Again, it is strange, as the financial system has been able to do so, most industrial sectors, food industries, and soon. Is it that the healthcare environment is so complex that this cannot be done? We would be surprised if this were the answer. It is true that the healthcare production function is complex, but the way of producing it is quite the same all around the world. Why is there not a common unit that enables comparisons across countries while accounting for unit price differences?

The introduction of costing and complete economic analysis in HTA production is uneven and rather poor in Catalonia and Spain. We have left these to the for-profit industries, and it is them who "set" these common prices and we all use them. More surprisingly, they have to ask the public sector for their unit prices to incorporate them in their databases. To us, it does not sound reasonable!

It is time we introduce policy and decision makers to more sophisticated economic analysis and to start the debate of explicit rationing by means of its cost and costeffectiveness. The same way we introduced evidence analysis, we may now introduce opportunity cost analysis in the policy arena and be prepared to debate with the public the social consequences.

Finally, the aim of our recommendations is changes in practice or in planning. However, we miss the opportunity to measure the impact of our recommendations and that has not been incorporated as a mandatory part of any report. Planning strategies do include impact analysis, but HTA does not. By missing this impact analysis, we all miss the opportunity to convince our policy makers of the need of HTA and its goodness.

\section{CONCLUSIONS}

The story of HTA in Catalonia shows a growing experience, and major landmarks have been established. Cultural changes have occurred and have been led by CAHTAR in the past two decades, but we may fail to fulfill our mission if we are not prepared to face the new and bigger challenges.

In the past two decades, Catalonia has contributed to the establishment of a robust methodology and evaluation culture. The tool is now there, but it is up to us to implement that tool while fulfilling the new needs of all actors in the health system, that is, the healthcare professionals, the managers, the policy and decision makers, the public and why not, the new needs of industry, to improve their research decisionmaking processes. Let us not stare proudly to our past while the future runs in front of us. 


\section{CONTACT INFORMATION}

Oriol de Solà-Morales, MD, MSc (osola@aatrm.catsalut. cat), Director, Catalan Agency for Health Technology Assessment and Research (CAHTAR), Roc Boronat 81-95, E-08024 Barcelona, Spain

Alicia Granados, MD, PhD (alicia_granados@merck. com), Member, Board of Directors, Catalan Agency for Health Technology Assessment and Research (CAHTAR), Roc Boronat 81-95, E-08024 Barcelona, Spain; HTA Policy and CR EEAA: MSD España, Josefa Valcarcel, 38, 28027 Madrid, Spain

\section{REFERENCES}

1. Aymerich M, Jovell AJ, Estrada MD. Revisió sistemàtica de l'evidència científica. In: Evidència científica i presa de decisions en Sanitat. Barcelona: Acadèmia de Ciències Mèdiques de Catalunya i de Balears; 1999:93-123.

2. Banta HD, Werkö L, Cranovsky R, et al. Report from the EUR-ASSESS Project. Int J Technol Assess Health Care. 1997;13:133-143.

3. Catalan A, Pellicer MA, Gené J. Nuevos medicamentos o novedades terapéuticas? El Comité de Evaluación de Nuevos
Medicamentos del Instituto Catalán de la Salud. Aten Primaria. 2000;26:636-640.

4. Granados A, Borràs JM. Technology assessment in Catalonia: Integrating economic appraisal. Soc Sci Med. 1994;38:16431646.

5. Granados A, Sampietro-Colom L, Asua J, Conde J, Vazquez Albertino R. Health technology assessment in Spain. Int J Technol Assess Health Care. 2000;16:532-559.

6. Granados A. Health technology assessment and clinical decision-making: Which is the best evidence? Int J Technol Assess Health Care. 1999;15:585-614.

7. Hailey D, Sampietro-Colom L, Marshall D, et al. The effectiveness of bone density measurement and associated treatments for prevention of fractures. An international collaborative review. Int J Technol Assess Health Care. 1998;14:237-254.

8. Larizgoitia I, Rodríguez JR, Granados A, et al. Determinantes en la toma de decisiones clínicas en atención primaria: Opinión de los profesionales. Aten Primaria. 1998;22:505-513.

9. Lehoux P, Battista RN, Granados A, et al. International Master's Program in health technology assessment and management: Assessment of the first edition (2001-2003). Int J Technol Assess Health Care. 2005;21:104-112.

10. Ley 14 /1986, de 25 de abril, General de Sanidad. Madrid: Boletín Oficial del Estado (BOE); núm. 102, de 29/04/1986. p. 15207-15224. 